\title{
Oxidised iron in garnets from the mantle transition zone
}

Ekaterina S. Kiseeva ${ }^{1,}{ }^{*}$, Denis M. Vasiukov ${ }^{2}$, Bernard J. Wood ${ }^{1}$, Catherine McCammon ${ }^{3}$, Thomas Stachel ${ }^{4}$, Maxim Bykov,5, Elena Bykova ${ }^{3,5}$, Alexander Chumakov ${ }^{6}$, Valerio Cerantola ${ }^{6}$, Jeff W. Harris ${ }^{7}$, Leonid Dubrovinsky ${ }^{3}$

1 - Department of Earth Sciences, University of Oxford, Oxford OX1 3AN, UK

2 - Laboratory of Crystallography, University of Bayreuth, D-95440 Bayreuth, Germany

3 - Bayerisches Geoinstitut, Universität Bayreuth, D-95440 Bayreuth, Germany

4 - Department of Earth and Atmospheric Sciences, University of Alberta, Edmonton, AB, T6G 2E3, Canada

5 - DESY Photon Science, Notkestrasse 85, DE-22607 Hamburg, Germany

6 - ESRF-The European Synchrotron, CS 40220, 38043, Grenoble, Cedex 9, France

7 - School of Geographical and Earth Sciences, University of Glasgow, Glasgow, G12 8QQ, UK

*corresponding author

\section{Abstract}

The oxidation state of iron in Earth's mantle is well known to depths of $\sim 200 \mathrm{~km}$, but has not been measured in samples from the lowermost upper mantle (200$410 \mathrm{~km}$ depth) or the transition zone (410-660 km). Here we use Synchrotron Mössbauer Source spectroscopy complemented by single crystal X-ray diffraction to make the first measurements of the oxidation state of Fe in inclusions of ultrahigh pressure majoritic garnet in diamond. The garnets show a pronounced increase in oxidation state with depth, with $\mathrm{Fe}^{3+} /\left(\mathrm{Fe}^{3+}+\mathrm{Fe}^{2+}\right)$ increasing from 0.08 at $\sim 240 \mathrm{~km}$ depth to 0.30 at $\sim 500 \mathrm{~km}$ depth. The latter majorites, which come from pyroxenitic bulk compositions, are twice as rich in $\mathrm{Fe}^{3+}$ as the most oxidised garnets from the shallow mantle. Corresponding oxygen fugacities are above the upper stability limit of Fe metal. This observation implies that the increase in oxidation state is not linked to the putative disproportionation of $\mathrm{Fe}^{2+}$ to $\mathrm{Fe}^{3+}$ plus Fe metal. Instead, the $\mathrm{Fe}^{3+}$ increases with depth are consistent with the hypothesis that carbonated fluids or melts are the oxidising agents responsible for the high $\mathrm{Fe}^{3+}$ contents of the inclusions.

\section{Introduction}

The Earth's peridotitic upper mantle contains about $6.3 \mathrm{wt} \% \mathrm{Fe}^{1}$ dominantly stored as 
$\mathrm{Fe}^{2+}$ in the main rock forming minerals, olivine, pyroxene, spinel and garnet. Analyses of these minerals from peridotite xenoliths and less abundant mantle pyroxenites using Mössbauer spectroscopy indicate that the $\mathrm{Fe}^{3+}$ content of fertile upper mantle is very low with $\mathrm{Fe}^{3+} /\left(\mathrm{Fe}^{3+}+\mathrm{Fe}^{2+}\right) \sim 0.0362$. In the case of ferric iron, spinel is a major host in the uppermost mantle and $\mathrm{Fe}^{3+}$ contents of this mineral are sufficiently high to be used to calculate the oxygen fugacity recorded by mantle peridotites using the olivineorthopyroxene-spinel oxybarometer ${ }^{3}$. The results indicate that the subcontinental lithospheric upper mantle exhibits oxygen fugacities close to the reference FMQ (fayalite-magnetite-quartz buffer) 3,4, while peridotites from close to subduction zones are about $1 \log \mathrm{fO}_{2}$ unit higher and suboceanic peridotites about $1 \log$ unit lower than $\mathrm{FMQ}^{2}$. At pressures above $2.8 \mathrm{GPa}$, spinel is replaced by garnet as the aluminous phase in peridotite. Mössbauer data on xenoliths from the deeper parts of the lithosphere ${ }^{5}$ indicate a general increase in $\mathrm{Fe}^{3+} /\left(\mathrm{Fe}^{2+}+\mathrm{Fe}^{3+}\right)$ of garnet with depth, with values of around 0.04 corresponding to about $100 \mathrm{~km}$ depth while at $200 \mathrm{~km}$ depth this ratio is 0.1 . When translated to oxygen fugacity, however, these results indicate a decline relative to FMQ with depth because of the increased stability of ferric iron in garnet at high pressure ${ }^{6}$. Extrapolation of the data to higher pressures implies that the $\mathrm{FeO}-\mathrm{Fe}$ (IW) buffer curve could be crossed in the mantle at depths below $250 \mathrm{~km}^{5}$, leading to the possibility of Fe-rich metal being stabilised in the mantle transition zone. This is an important suggestion, consistent with observations of Fe-rich metallic inclusions in diamond from depths of the base of the lithospheric mantle 7,8 and $>360 \mathrm{~km}^{9}$. Similar deep diamonds contain inclusions of garnet, the major silicate inclusion from the transition zone. Given the role of garnet as a key host for $\mathrm{Fe}^{3+}$ in the upper mantle, it is important to determine how the $\mathrm{Fe}^{3+}$ contents and oxygen fugacities recorded by garnet inclusions in diamond from depths $>250 \mathrm{~km}$ relate to those derived from upper mantle xenoliths (from $<200 \mathrm{~km}$ ) and to the apparent stability of Fe-rich alloys and other indicators of ultra-reduced conditions ${ }^{10}$ in some very high pressure assemblages. The purpose of our study was, therefore, to determine how the oxidation state of iron in garnet (included in diamond) from the mantle varies as a function of depth and to translate measured oxidation states to oxygen fugacities.

In order to determine the oxidation state of Fe in garnet inclusions in diamond, we used single crystal X-ray diffraction analysis combined with Synchrotron Mössbauer Source (SMS) spectroscopy (beamline ID18 at the European Synchrotron Radiation Facility, Grenoble). The diamonds were polished to expose the garnet prior to analysis. We obtained spectra (Extended Data Figs. 1-2 and Extended Data Table 1) of 13 small (0.1- 

$0.3 \mathrm{~mm}$ in diameter) majoritic inclusions in diamonds from the Jagersfontein kimberlite (South Africa) (Extended Data Fig. 3). The inclusions were initially studied by X-ray diffraction at the Extreme Conditions Beamline (ECB), P02.2, at the PETRA III synchrotron, Hamburg and confirmed as predominantly monophase garnet single crystals or (in very few cases) as aggregates of single crystals (Extended Data Tables 24). There is good agreement between determinations of $\mathrm{Fe}^{3+} /\left(\mathrm{Fe}^{2+}+\mathrm{Fe}^{3+}\right)$ using Mössbauer spectroscopy and single crystal X-ray refinement as well as calculations based on composition assuming stoichiometry (Extended Data Table 5). In several samples an unexpectedly high content of ferric iron was detected (up to $\sim 30 \%$ of total iron) and requires further detailed consideration.

In the commonest case of a single garnet inclusion there is no unique geobarometer enabling pressure to be unequivocally determined. However, at pressures beyond 7.5 GPa coexisting pyroxene dissolves progressively into garnet as the majoritic components $(\mathrm{Mg}, \mathrm{Fe})_{4} \mathrm{Si}_{4} \mathrm{O}_{12}$ and $\mathrm{Na}_{2} \mathrm{MgSi}_{5} \mathrm{O}_{12}$. The concentrations of these components in majoritic garnet give an equilibrium pressure provided pyroxene is present in the source ${ }^{11}$. In the absence of pyroxene in the source, the derived pressure is a minimum estimate. In subducted basaltic lithologies the pyroxene to garnet transformation produces a garnetite of $\sim 95 \%$ majoritic garnet and $\sim 5 \%$ stishovite at about $500 \mathrm{~km}$ depth ${ }^{12,13}$, while in rocks with peridotitic composition majoritic garnet forms a bimineralic rock with the high-pressure form of $(\mathrm{Mg}, \mathrm{Fe})_{2} \mathrm{SiO}_{4}$ (wadsleyite or ringwoodite) ${ }^{14}$. There are, however, significant compositional differences between garnets from the two end-member lithologies, with the $(\mathrm{Mg}, \mathrm{Fe})_{4} \mathrm{Si}_{4} \mathrm{O}_{12}$ substitution dominating in peridotitic rocks while basaltic or eclogitic compositions produce garnet with considerable amounts of $\mathrm{Na}_{2} \mathrm{MgSi}_{5} \mathrm{O}_{12}$ component (Fig. 1). Perhaps surprisingly, the compositions of most inclusions from diamond appear to come from a third rock type, pyroxenite, which is intermediate in composition between peridotite and eclogite ${ }^{15}$. Pyroxenite lenses are common in mantle peridotites ${ }^{16}$ and considered to be produced by reaction between peridotitic and eclogitic compositions, possibly through the agency of carbonated melts ${ }^{17,18}$. Although following the "peridotitic" trend of Fig 1, pyroxenitic garnets are lower in $\mathrm{Cr}_{2} \mathrm{O}_{3}$ and $\mathrm{Mg \#}(=\mathrm{Mg} / \mathrm{Mg}+\mathrm{Fe})$ and higher in $\mathrm{CaO}$ than peridotitic garnets. The garnet inclusions we have studied are, in common with most other majorite inclusions, pyroxenitic in composition in that they follow the peridotite "trend" on a plot of $\mathrm{M}^{2+}$ versus ( $\left.\mathrm{M}^{4+}+\mathrm{M}^{5+}\right)$ (Fig. 1), but are low in $\mathrm{Cr}_{2} \mathrm{O}_{3}(0.03-0.34$ wt\%) and $\mathrm{Mg \#} \mathrm{(0.65-}$ 0.81) and high in $\mathrm{CaO}$ (4.62-11.2 wt\%). As far as we are aware, no majoritic garnets of peridotitic composition have yet been reported as inclusions in diamond from the 
mantle transition zone. This implies a genetic connection, explored in more detail

110 elsewhere ${ }^{17,18}$ between the minor mantle rock type pyroxenite, and the diamond host.

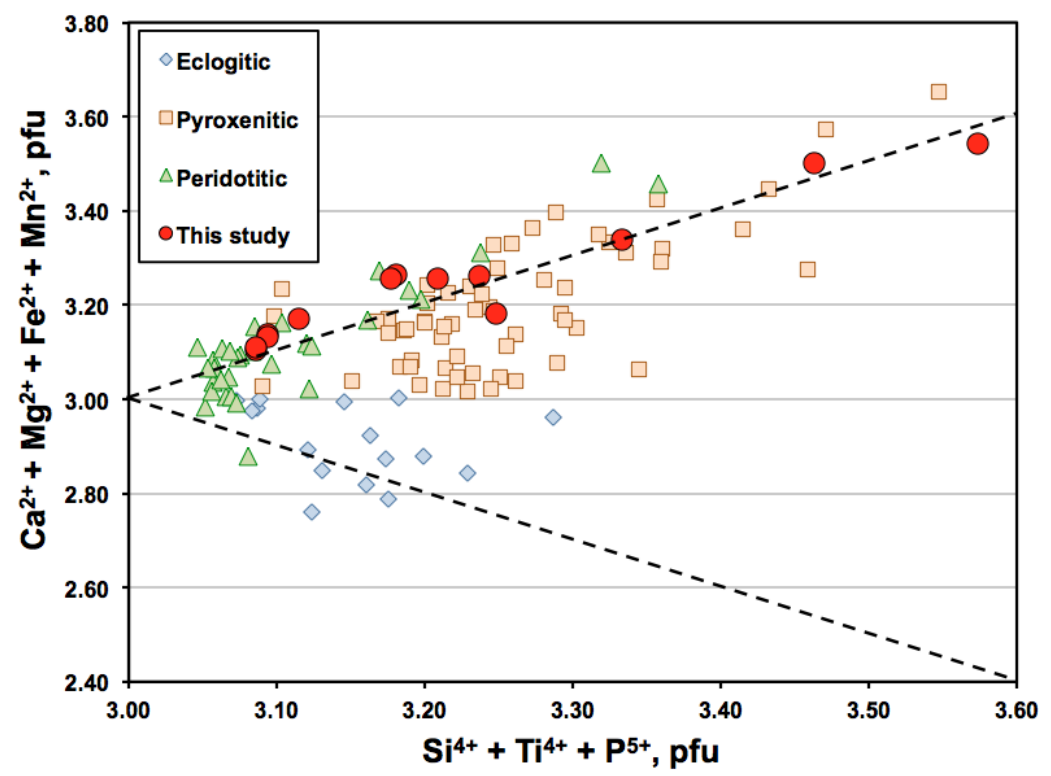

Figure 1. Chemical composition (in cations per 12-oxygen formula unit) of majoritic garnet inclusions in diamonds worldwide (literature data from ref. 15). Inclusions studied here from the Jagersfontein kimberlite are shown by red circles. In order to compare compositions with those of previous studies, all iron has been calculated as $\mathrm{Fe}^{2+}$.

Our measurements show an increase in $\mathrm{Fe}^{3+} /\left(\mathrm{Fe}^{2+}+\mathrm{Fe}^{3+}\right)$ with increasing amount of majorite substitution and hence pressure (Fig. 2). Assuming the presence of pyroxene in the pyroxenitic diamond substrates, garnet compositions yield pressures of formation of 7.7-17.9 GPa using the Beyer and Frost majorite geobarometer ${ }^{11}$. These are minimum pressures, however, because the majoritic garnet equilibrium with pyroxene has not been demonstrated. Interestingly, Figure 2 shows that $\mathrm{Fe}^{3+} /\left(\mathrm{Fe}^{2+}+\mathrm{Fe}^{3+}\right)$ is extremely well correlated with calculated pressure, increasing from 0.08 at $7.7 \mathrm{GPa}$ to values between 0.30 at $16 \mathrm{GPa}$ and 0.27 at $18 \mathrm{GPa}$. Note that at least 4 of these 13 garnets were formed at (minimum) pressures of 13 to $18 \mathrm{GPa}$ and, therefore crystallised in the transition zone (410-660 km depth). It is also interesting to note that our measured $\mathrm{Fe}^{3+} /\left(\mathrm{Fe}^{2+}+\mathrm{Fe}^{3+}\right)$ values define a clear extension of the trend apparent in the data from peridotite xenoliths crystallised at lower pressures and that Fe from the transition zone garnets is at least twice as oxidised as in any garnet from xenoliths of subcratonic lithospheric mantle. 


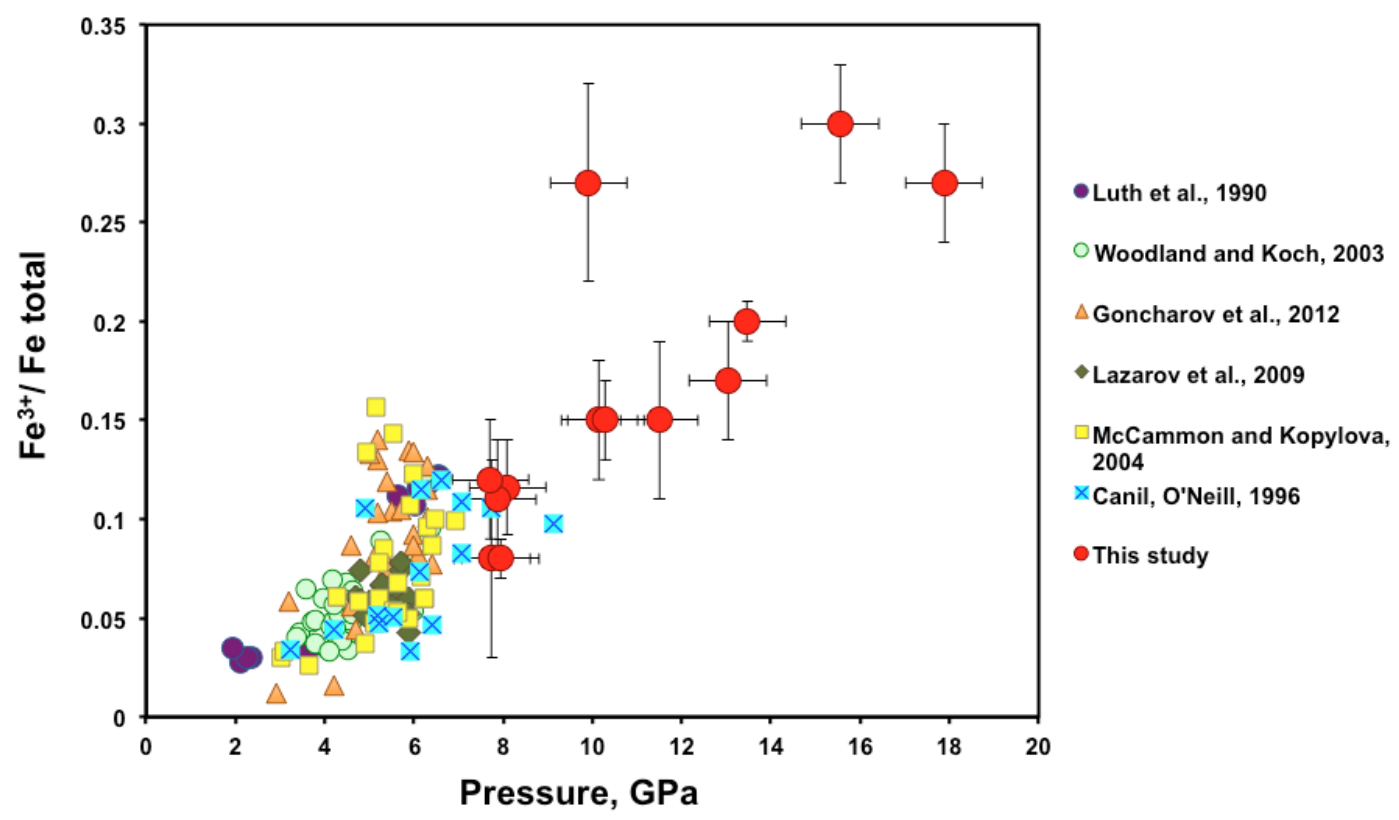

134 Fig. 2. Ferric iron contents of majoritic garnets from Jagersfontein diamonds compared to

135 lithospheric garnets from peridotite xenoliths. All ferric iron contents determined by Mössbauer 136 spectroscopy ${ }^{5,19-23}$.

138 In order to estimate the oxygen fugacities represented by these $\mathrm{Fe}^{3+}$ - bearing inclusions 139 we looked for the simplest equilibrium available containing the fewest number of 140 activities undefined by garnet composition:

In this case we need to define the activity of $\mathrm{SiO}_{2}$, which we assumed was slightly $[0.01$ $\log$ units) above the forsterite-enstatite equilibrium and hence consistent with the garnets being close to equilibrium with peridotite. Although we recognise that this is a crude assumption, we show below that it yields (correctly) oxygen fugacities consistent with the stability of metallic Fe in experiments performed in iron capsules on similar compositions by Rohrbach et al ${ }^{24}$. We took thermodynamic data for equilibrium (1)

151 from the database of Holland and Powell and Holland et al ${ }^{25,26}$ and calculated oxygen

152 fugacities for pressures given by the Beyer-Frost geobarometer ${ }^{11}$ at temperatures

153 corresponding to a mantle adiabat with a potential temperature of $1350^{\circ} \mathrm{C}^{27}$ (Methods).

154 Results (Fig. 3) indicate that the analysed garnets correspond to oxygen fugacities

155 from $\sim 0.26 \log f \mathrm{O}_{2}$ units below to about $3 \log f \mathrm{O}_{2}$ units above the $\mathrm{Fe}-\mathrm{FeO}$ (IW) buffer, 
156 implying that they were not in equilibrium with Fe metal and not oxidised by

157 disproportionation of $\mathrm{Fe}^{2+}$ to $\mathrm{Fe}^{3+}$ plus $\mathrm{Fe}^{0}$ (Methods). We checked our calculation

158 method and assumptions using data from experiments in which garnets were

159 synthesised in equilibrium with $\mathrm{Fe}$ metal and their $\mathrm{Fe}^{3+}$ contents measured ${ }^{24}$. In this

160 case (Fig 3), 4 of the 5 experiments give calculated oxygen fugacities, as expected, just

161 below $\mathrm{Fe}-\mathrm{FeO}$ equilibrium. This test indicates that our methods are reasonably accurate

162 and our conclusions justified, even though uncertainties in activity expressions imply

163 about $1 \log$ unit of uncertainty in absolute $\mathrm{fO}_{2}$. Note that any actual error in activity

164 expressions will lead to all points moving in the same direction, thus preserving the

165 trends of Figure 3.

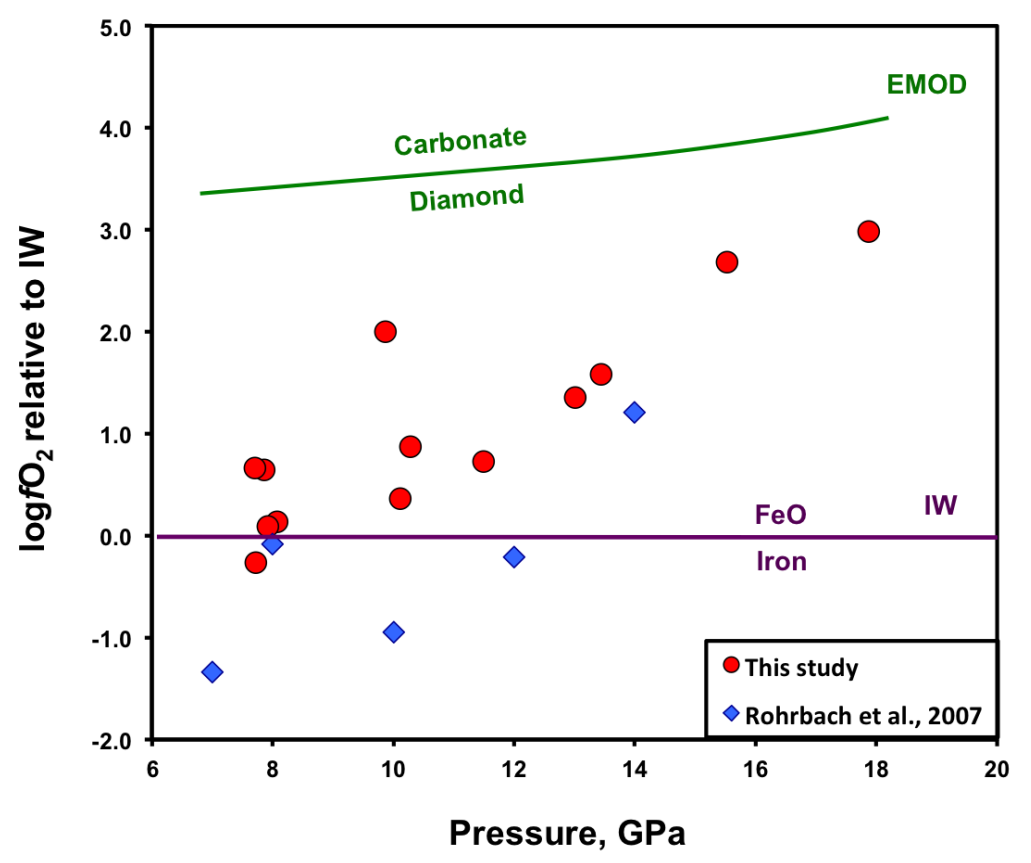

Fig. 3. Calculated oxygen fugacities of the majoritic inclusions and of garnets crystallised in

168 coexistence with Fe metal ${ }^{24}$ relative to the EMOD and Fe-FeO (IW) buffers. See text and Methods for

169 details of the calculation and error estimates.

171 Since $\mathrm{Fe}^{2+}$ disproportionation appears not to be responsible, the source of the oxidising 172 agent which generated the high $\mathrm{Fe}^{3+} /\left(\mathrm{Fe}^{2+}+\mathrm{Fe}^{3+}\right)$ ratios of the transition zone garnets is

173 of considerable interest. It has previously been suggested that the pyroxenite substrates

174 in which the garnets and their host diamonds crystallised were generated by reaction

175 between subducted eclogite and peridotite aided by carbonate melt 17,18 and that

176 diamond and oxidised majoritic garnet are products of this interaction. For this reason

177 we compare our results (Fig. 3) to a carbon-carbonate equilibrium relevant to the

178 deeper upper mantle: 
181 magnesite enstatite olivine diamond

183 We used tabulated thermodynamic data 25,26 and corrected for the effect of the phase

184 change from olivine to wadsleyite at $\sim 14 \mathrm{GPa}$. Figure 3 shows that our inclusions are in

185 the (reduced) diamond stability field and that they approach EMOD with increasing

186 pressure, which means that oxidation of $\mathrm{Fe}^{2+}$ during reduction of carbonate in a fluid or

187 melt phase is a plausible mechanism for generating the $\mathrm{Fe}^{3+}$ present in the garnets, as

188 also suggested in a recent study ${ }^{28}$. The inclusions have $\delta^{18} \mathrm{O}_{\text {vSMow values between }+8.6}$

189 and $+10 \% 0^{29}$, consistent with a protolith which contains a substantial proportion of

190 subducted oceanic crust, although is no longer eclogitic. The LREE depleted and fairly

191 flat chondrite normalised MREE-HREE patterns ${ }^{30}$ of the majoritic garnet inclusions

192 suggest that during subduction, their protolith was chemically depleted in incompatible

193 trace elements, including LREE, during partial melting in the garnet stability field.

195 In conclusion, we have shown that, in the upper mantle and transition zone, there is a

196 systematic increase with depth in the oxidation state of iron in garnet from pyroxenitic

197 bulk compositions. Although the volumetric proportion of pyroxenite in this part of the

198 mantle is unknown, we note that these are the only available garnet inclusions that

199 demonstrably come from the mantle transition zone and are hence the only indication of

200 oxygen fugacity and oxidation state in this region of the mantle. The deepest samples

201 (from $500 \mathrm{~km}$ depth) have $\mathrm{Fe}^{3+} /\left(\mathrm{Fe}^{3+}+\mathrm{Fe}^{2+}\right.$ ) of 0.30 , more than double the ferric iron

202 content of any garnet from the shallower $(<200 \mathrm{~km})$ peridotitic mantle. These ferric iron

203 contents correspond to oxygen fugacities above the Fe-FeO (IW) buffer, which means

204 that the high $\mathrm{Fe}^{3+}$ contents were not generated by disproportionation of $\mathrm{Fe}^{2+}$ to $\mathrm{Fe}^{3+}$ and

$205 \mathrm{Fe}^{0}$. With increasing depth relative oxygen fugacities increase and approach the carbon-

206 carbonate equilibrium, suggesting that carbonate was the oxidising agent responsible

207 for generating the high $\mathrm{Fe}^{3+}$ of these mantle garnets.

Acknowledgements.

210 We thank Tim Holland for checking some of our calculations and Dan Frost for providing

211 his spreadsheet for oxygen fugacity calculations using garnet equilibria, Andreas

212 Schönleber for discussion of XRD results and Dariia Simonova for assistance during

213 Mössbauer experiments. We acknowledge support from European Research Council

214 grant 267764 to BJW and the NERC grant NE/L010828/1 to ESK. Financial support was

215 provided to LD and CM through grants from the DFG and BMBF. We acknowledge the 
216 European Synchrotron Radiation Facility for provision of synchrotron radiation

217 facilities.

219 Notes of contribution.

220 Work was initiated and planned by ESK and LD; TS and JH provided the samples and

221 their detailed description; X-ray diffraction measurements were performed by MB, DV,

222 EB, and LD; diffraction data were processed and analyzed by DV, MB, EB, and LD;

223 Mössbauer spectra were collected by DV, VC, AC, CM, and LD; Mössbauer spectra were

224 processed and analyzed by DV, CM, and LD; ESK and BW interpreted the data, performed

225 the thermodynamic calculations and prepared the manuscript. All co-authors read,

226 commented and approved of the manuscript.

\section{References}

2291 McDonough, W. F. \& Sun, S. S. The Composition of the Earth. Chemical Geology $230 \quad$ 120, 223-253 (1995).

2312 Canil, D. et al. Ferric iron in peridotites and mantle oxidation states. Earth and

232 Planetary Science Letters 123, 205-220, doi:10.1016/0012-821x(94)90268-2

233 (1994).

2343 Wood, B. J., Bryndzia, L. T. \& Johnson, K. E. Mantle oxidation state and Its

235 relationship to tectonic environment and fluid speciation. Science 248, 337-345, 236 doi:10.1126/science.248.4953.337 (1990).

2374 Frost, D. J. \& McCammon, C. A. The redox state of Earth's mantle. Annual Review

$238 \quad$ of Earth and Planetary Sciences 36, 389-420 (2008).

2395 Woodland, A. B. \& Koch, M. Variation in oxygen fugacity with depth in the upper

240 mantle beneath the Kaapvaal craton, Southern Africa. Earth and Planetary

$241 \quad$ Science Letters 214, 295-310 (2003).

2426 Gudmundsson, G. \& Wood, B. J. Experimental tests of garnet peridotite oxygen

243 barometry. Contributions to Mineralogy and Petrology 119, 56-67,

244 doi:10.1007/bf00310717 (1995).

2457 Jacob, D. E., Kronz, A. \& Viljoen, K. S. Cohenite, native iron and troilite inclusions

246 in garnets from polycrystalline diamond aggregates. Contributions to Mineralogy

247 and Petrology 146, 566-576, doi:10.1007/s00410-003-0518-2 (2004).

2488 Sobolev, N. V., Efimova, E. S. \& Pospelova, L. N. Native iron in diamonds of

249 Yakutia and its paragenesis. Geologiya I Geofizika 22, 25-28 (1981).

2509 Smith, E. M. et al. Large gem diamonds from metallic liquid in Earth's deep

251 mantle. Science 354, 1403-1405, doi:10.1126/science.aal1303 (2016). 
253 average mantle peridotites and in podiform chromitites: a thermodynamic model for moissanite (SiC) formation. Contributions to Mineralogy and Petrology 171, 1-17, doi:10.1007/s00410-016-1253-9 (2016).

11 Beyer, C. \& Frost, D. J. The depth of sub-lithospheric diamond formation and the redistribution of carbon in the deep mantle. Earth and Planetary Science Letters 461, 30-39, doi:http://dx.doi.org/10.1016/j.epsl.2016.12.017 (2017). Irifune, T. \& Ringwood, A. E. in High-Pressure Research in Mineral Physics Vol. 1 (eds M.H. Manghnani \& Y Syono) 235-246 (Terra Scientific, 1987). Wood, B. J., Kiseeva, E. S. \& Matzen, A. K. Garnet in the Earth's Mantle. Elements 9 , 421-426 (2013).

Irifune, T. \& Ringwood, A. E. Phase transformations in a harzburgite composition to $26 \mathrm{GPa}$ - implications for dynamical behavior of the subducting slab. Earth and Planetary Science Letters 86, 365-376 (1987). Kiseeva, E. S. et al. Metapyroxenite in the mantle transition zone revealed from majorite inclusions in diamonds. Geology 41, 883-886, doi:Doi 10.1130/G34311.1 (2013). petrogenesis of diamond facies pyroxenites from the Beni Bousera peridotite massif, North Morocco. Journal of Petrology 34, 125-172 (1993).

Kiseeva, E. S., Wood, B. J., Ghosh, S. \& Stachel, T. The pyroxenite-diamond connection. Geochemical Perspectives Letters 2, 1-9, doi:http://dx.doi.org/10.7185/geochemlet.1601 (2016). Thomson, A. R., Walter, M. J., Kohn, S. C. \& Brooker, R. A. Slab melting as a barrier to deep carbon subduction. Nature 529, 76-79 (2016).

Canil, D. \& ONeill, H. S. C. Distribution of ferric iron in some upper-mantle assemblages. Journal of Petrology 37, 609-635, doi:Doi 10.1093/Petrology/37.3.609 (1996).

20 Goncharov, A. G., Ionov, D. A., Doucet, L. S. \& Pokhilenko, L. N. Thermal state, oxygen fugacity and $\mathrm{C}-\mathrm{O}-\mathrm{H}$ fluid speciation in cratonic lithospheric mantle: New data on peridotite xenoliths from the Udachnaya kimberlite, Siberia. Earth and Planetary Science Letters 357, 99-110, doi:10.1016/j.epsl.2012.09.016 (2012). Lazarov, M., Woodland, A. B. \& Brey, G. P. Thermal state and redox conditions of the Kaapvaal mantle: A study of xenoliths from the Finsch mine, South Africa. Lithos 112, 913-923, doi:10.1016/j.lithos.2009.03.035 (2009). 

garnets - implications for thermobarometry and for the oxidation state of the mantle. Contributions to Mineralogy and Petrology 104, 56-72, doi:Doi 10.1007/Bf00310646 (1990).

29123 McCammon, C. \& Kopylova, M. G. A redox profile of the Slave mantle and oxygen 292 fugacity control in the cratonic mantle. Contributions to Mineralogy and Petrology 148, 55-68 (2004).

$29424 \quad$ Rohrbach, A. et al. Metal saturation in the upper mantle. Nature 449, 456-458 (2007).

29625 Holland, T. J., Hudson, N. F., Powell, R. \& Harte, B. New thermodynamic models and calculated phase equilibria in NCFMAS for basic and ultrabasic compositions through the transition zone into the uppermost lower mantle. Journal of Petrology 54, 1901-1920, doi:Doi 10.1093/Petrology/Egt035 (2013).

26 Holland, T. J. B. \& Powell, R. An improved and extended internally consistent thermodynamic dataset for phases of petrological interest, involving a new equation of state for solids. Journal of Metamorphic Geology 29, 333-383, doi:Doi 10.1111/J.1525-1314.2010.00923.X (2011). Mckenzie, D. \& Bickle, M. J. The volume and composition of melt generated by extension of the lithosphere. Journal of Petrology 29, 625-679 (1988).

$$
\text { Xu, C. et al. Recovery of an oxidized majorite inclusion from Earth's deep }
$$
asthenosphere. Science Advances 3, doi:10.1126/sciadv.1601589 (2017). majorite constrains a crustal origin of transition zone diamonds. Geochemical Perspectives Letters 1, 65-74, doi:http://dx.doi.org/10.7185/geochemlet.1507 (2015).

Tappert, R. et al. Diamonds from Jagersfontein (South Africa): messengers from the sublithospheric mantle. Contributions to Mineralogy and Petrology 150, 505522 (2005). 


\section{METHODS}

316 Samples. The garnet inclusions in diamonds investigated in this study originate from the Jagersfontein kimberlite in South Africa (more details about the host diamonds, compositions, rare earth element (REE) patterns etc. are given in Ref. 30). The inclusions were released by crushing the host diamonds, mounted in epoxy disks with $0.7 \mathrm{~mm}$ thickness supported by brass rings and then polished. All measurements described here were performed on the samples mounted in epoxy. The size of the inclusions studied vary from about $60 \mu \mathrm{m}$ in diameter and $20 \mu \mathrm{m}$ thick to $300 \mu \mathrm{m}$ in lateral dimensions and about $300 \mu \mathrm{m}$ thick.

Mössbauer spectroscopy. Mössbauer absorption spectra were collected at ambient temperature at the Nuclear Resonance beamline (ID18) at the European Synchrotron Radiation Facility (Grenoble, France) using a Synchrotron Mössbauer Source (SMS) ${ }^{31}$. The experiment was conducted in transmission geometry and folded spectra contain 512 channels. The typical beam size was $16 \times 20 \mu \mathrm{m}^{2}$ full width at half maximum (FWHM). The line width of the SMS was determined before and after collection of each spectrum of the sample by measuring the reference single line absorber $\left(\mathrm{K}_{2} \mathrm{Mg}^{57} \mathrm{Fe}(\mathrm{CN})_{6}\right)$. More information about sample mounting and alignment procedure is given in Ref. 32. Each spectrum was collected for 4 to 12 hours.

The Mössbauer spectra were fitted using MossA software ${ }^{33}$ version 1.01a with the full transmission integral assuming a Lorentzian-squared line shape of the SMS. The fitted parameters were centre shift (CS), FWHM, intensity (area), quadrupole splitting (QS), and component intensity ratio of the main doublet ( $a 12$, where the asymmetry is due to the Goldanskii-Karyagin effect for iron located in the distorted cubic X-position of the garnet structure, see Ref. 34; there is no effect for iron in the octahedral Y-site). The centre shift values are reported relative to $\alpha$-iron at ambient conditions. Iron cations in two crystallographically distinct sites in the garnet structure may have different recoil-freefractions ("f-factors") $)^{35,36}$. The Debye approximation was used to correct for the different $f$ factors, where values of the effective Debye temperatures for X-and Y-sites were taken from Refs. 35 and 36. Additional absorption in the JF-22A spectrum was fit to a quadrupole doublet and assigned to $\mathrm{Fe}^{2+}$ in clinopyroxene based on the hyperfine parameters. X-ray optical components at the ID18 beamline, contain very small amounts (ppm level) of iron. Generally, this amount of iron does not affect SMS spectra due to the strong signal from the sample. However, due to small size of the samples studied and the low natural abundance of ${ }^{57} \mathrm{Fe}$, the signal from the sample was sufficiently weak that spectral contamination from iron in the X-ray optical components could be detected. In order to account for this effect at each experimental run (i.e., for different combinations of X-ray optical components), SMS spectra were measured without any sample so that Mössbauer absorption due to the optical components could be accurately determined for each of the garnet SMS spectra.

$\mathrm{X}$-ray diffraction. X-ray diffraction (XRD) measurements were performed at the Extreme Conditions Beamline P02.2 at PETRA III (Hamburg, Germany) ${ }^{37}$. Data were acquired with a PerkinElmer XRD1621 flat panel detector, X-ray beam-size $5 \times 8 \mu \mathrm{m}^{2}$ (FWHM), and wavelength $\lambda=0.29464 \AA$. XRD "wide-scan" images were collected during continuous rotation of the samples from -20 to $+20^{\circ}$ on the omega axis; single crystal data collection experiments were performed by narrow $0.5^{\circ}$ scanning $\omega$-scanning in the range from $-35^{\circ}$ to $+35^{\circ}$. Data integration and absorption corrections were performed with CrysAlisPro ${ }^{38}$ software version 171.38.43. Refinement was performed using the JANA2006 ${ }^{39}$ version from 25.10.2015.

XRD data analysis. Analysis of diffraction patterns shows that all garnet inclusions studied are single crystals, mostly mono-domain, where only samples JF-58B and JF-22A contain more than two domains (but all with the same lattice parameters within the measurement uncertainty). Within the detection limits of X-ray diffraction, all samples except for three are monomineralic. Samples JF-44B and JF-58B show the presence of a small amount of polycrystalline phase(s) (strongest intensity of impurity powder diffraction lines are within 
$0.5 \%$ of the (420) diffraction line of garnet). Sample JF-84A contains single crystal domains of clinopyroxene ( ppace group $C 2 / c, a=9.650(4), b=8.828(2), c=5.2481(11) \AA, \beta=$ 106.91(3), $\left.\mathrm{V}=427.8(2) \AA^{3}\right)$. However, its relative phase fraction is negligible and its presence does not affect the structure refinement of XRD data. The contribution to the Mössbauer spectrum is negligible within the statistics of the data. The structural analysis of garnets is a well established method to study the distribution of elements over different crystallographic sites. For this study the amount of iron in the different structural positions is particularly relevant. Accurate structure refinements provide an average atomic scattering factor in the different crystallographic sites, thus imposing constraints on the types and amounts of elements in the sites. Silicate garnets have the general formula $\mathrm{X}^{2+}{ }_{3} \mathrm{Y}^{3+}{ }_{2}\left(\mathrm{SiO}_{4}\right)_{3}$ and crystallize in the cubic structure $(\mathrm{I} a \overline{3} d$ space group). The octahedral $\mathrm{Y}$-site is usually populated by a trivalent cation $\left(\mathrm{Al}^{3+}, \mathrm{Fe}^{3+}, \mathrm{Cr}^{3+}\right)$ and at high pressure could accommodate (as in majorite) $\mathrm{Si}^{4+}$ (balanced by $\mathrm{Mg}^{2+}$, in particular). Divalent cations $\left(\mathrm{Mg}^{2+}, \mathrm{Ca}^{2+}, \mathrm{Fe}^{2+}, \mathrm{Mn}^{2+}\right.$, etc.) occupy the distorted $\mathrm{X}$-site. Natural samples have complex chemical compositions. Even if one assumes that the contributions by $\mathrm{Na}, \mathrm{Mn}, \mathrm{Cr}$, and Ti to diffraction intensity is negligible (total up to $\sim 3$ at $\%$ in some samples), it is not possible to simultaneously refine the occupancies of four different atoms ( $\mathrm{Mg}, \mathrm{Fe}, \mathrm{Al}, \mathrm{Si})$ in the $\mathrm{Y}$ site and three atoms $(\mathrm{Ca}, \mathrm{Mg}, \mathrm{Fe})$ in the $\mathrm{X}$-site. Based on the known crystal chemistry of silicate garnet, all structural positions may be assumed to be fully occupied and charge (valence) balanced. Unambiguous refinements of iron occupancy in the X-and Y-sites are not possible and require information about the amount of other components from chemical analysis. We tested different combinations of constraints for sample JF-22a, and all give the same outcome within uncertainty $(\sim 0.5 \%)$. In the final model, we performed structural refinements of all garnets with the following composition constraints: $(i)$ each crystallographic site of garnet is fully occupied, (ii) only $\mathrm{O}, \mathrm{Si}, \mathrm{Mg}, \mathrm{Al}, \mathrm{Fe}$ and $\mathrm{Ca}$ are considered and the presence of other elements is neglected, (iii) in the Y-site, $\mathrm{Mg}, \mathrm{Si}$ and $\mathrm{Al}$ are refined as a single "Al" atom (X-ray scattering by equiproportional mixture of Si and Mg approximately the same as scattering by $\mathrm{Al}$ ), and (iiii) the amount of $\mathrm{Ca}$ in the $\mathrm{X}$-site is fixed based on the microprobe data.

Overall, there is good (within $3 \sigma$ ) agreement between determinations of $\mathrm{Fe}^{3+}$ content in all garnets studied by Mössbauer spectroscopy and X-ray diffraction as well as calculations based on composition assuming stoichiometry. We note that the $\mathrm{Fe}^{3+}$ content derived from Mössbauer spectroscopy is systematically higher than the amount obtained from X-ray diffraction data. The reasons for this minor inconsistency could be simplifications (assumptions) made during the structural refinements and/or complications in the analysis of overlapping components in SMS spectra (in particular the impurity signal from iron in the Xray optical components).

Thermodynamic calculations. All end-member thermodynamic data for our calculations, except that of the Fe-FeO (IW) reaction were taken from the work of Holland and Powell and Holland et $\mathrm{al}^{25,26}$. We used the equilibrium:

$$
\begin{aligned}
& 2 \mathrm{Ca}_{3} \mathrm{Al}_{2} \mathrm{Si}_{3} \mathrm{O}_{12}+4 / 3 \mathrm{Fe}_{3} \mathrm{Al}_{2} \mathrm{Si}_{3} \mathrm{O}_{12}+2.5 \mathrm{Mg}_{4} \mathrm{Si}_{4} \mathrm{O}_{12}+\mathrm{O}_{2}=2 \mathrm{Ca}_{3} \mathrm{Fe}_{2} \mathrm{Si}_{3} \mathrm{O}_{12}+10 / 3 \mathrm{Mg}_{3} \mathrm{Al}_{2} \mathrm{Si}_{3} \mathrm{O}_{12}+4 \mathrm{SiO}_{2} \\
& \text { Garnet } \\
& \text { Garnet } \\
& \text { Garnet } \\
& \text { Garnet }
\end{aligned}
$$

to estimate the oxygen fugacities at which the garnet inclusions were formed. Since the inclusions do not contain a $\mathrm{SiO}_{2}$ phase we need to estimate the activity of this component. We approximated this activity using end-member data for the reaction:

$$
\underset{\text { Olivine/wadsleyite }}{\mathrm{Mg}_{2} \mathrm{SiO}_{4}}+\underset{\text { Enstatite }}{\mathrm{SiO}_{2}}=\underset{\mathrm{Mg}_{2} \mathrm{Si}_{2} \mathrm{O}_{6}}{\mathrm{~S}_{\text {a }}}
$$

Coexistence of olivine and enstatite, as in a mantle peridotite, defines the activity of $\mathrm{SiO}_{2}$. In this case we used stishovite as our $\mathrm{SiO}_{2}$ end member so that $\mathrm{SiO}_{2}$ activities are expressed relative to this standard state. Since we do not observe olivine and orthopyroxene in the garnet inclusions we arbitrarily raised $\mathrm{SiO}_{2}$ activity by $0.01 \log$ units relative to olivine (wadsleyite above $13 \mathrm{GPa}$ ) stability. 
Using a standard state of the pure phase at the pressure and temperature of interest we followed the methods of Stagno et $\mathrm{al}^{40}$ to compute activities of the $\mathrm{Ca}_{3} \mathrm{Al}_{2} \mathrm{Si}_{3} \mathrm{O}_{12}$, $\mathrm{Fe}_{3} \mathrm{Al}_{2} \mathrm{Si}_{3} \mathrm{O}_{12}, \mathrm{Mg}_{3} \mathrm{Al}_{2} \mathrm{Si}_{3} \mathrm{O}_{12}$ and $\mathrm{Ca}_{3} \mathrm{Fe}_{2} \mathrm{Si}_{3} \mathrm{O}_{12}$ components from the compositions of the garnet inclusions. For the majorite component $\mathrm{Mg}_{4} \mathrm{Si}_{4} \mathrm{O}_{12}$ we computed activities from the garnet compositions using 2 possible expressions:

$$
\begin{aligned}
& R T \ln a_{M g_{4} S i_{4} O_{12}}^{g t}=R T \ln 4 x_{M g}^{c 3} x_{S i}^{o 2}+R T \ln {\underset{M g}{g t} S i_{4} O_{12}}_{R T}^{g t} \\
& R T \ln a_{M g_{4} S i_{4} O_{12}}^{g t}=R T \ln 4 x_{M g}^{c 3} \cdot x_{M g}^{o} x_{S i}^{o}+R T \ln { }_{M g_{4} S i_{4} O_{12}}^{o t}
\end{aligned}
$$

In equation 3, $x_{M g}^{c}, x_{M g}^{o}, x_{S i}^{o}$ refer to the atomic fractions of $\mathrm{Mg}$ and $\mathrm{Si}$ in the cubic (c) and octahedral (o) sites and the factor 4 normalises so that pure $\mathrm{Mg}_{4} \mathrm{Si}_{4} \mathrm{O}_{12}$ has activity 1.0. The first expression assumes stoichiometric substitution of $\mathrm{Mg}_{4} \mathrm{Si}_{4} \mathrm{O}_{12}$ into garnet so that there are equal mole fractions of $\mathrm{Mg}$ and $\mathrm{Si}$ on the octahedral site. The second expression is more realistic in allowing for different fractions of $\mathrm{Mg}$ and $\mathrm{Si}$ on the octahedral sites, but is impossible to compute exactly because the partitioning of $\mathrm{Fe}^{2+}$ and $\mathrm{Mg}$ between cubic and octahedral sites cannot be determined exactly by either stoichiometry or XRD.

The activity coefficient, $\stackrel{g t}{\mathrm{Mg}_{4} \mathrm{Si}_{4} \mathrm{O}_{12}}$ was calculated using the regular solution parameters from Holland et $\mathrm{al}^{25}$. Note, however, that these contain no reciprocal term ${ }^{40}$ and no terms involving $\mathrm{Fe}^{3+}$.

We used our analyses to assign atoms to sites in the normal way:

Cubic: $\mathrm{Ca}, \mathrm{Mg}, \mathrm{Fe}^{2+}, \mathrm{Mn}$

Tetrahedral: $\mathrm{Si}$

Octahedral, $\mathrm{Al}, \mathrm{Cr}, \mathrm{Fe}^{3+}$, excess $\mathrm{Si}$ from tetrahedral and excess $\left(\mathrm{Mg}+\mathrm{Fe}^{2+}\right)$ from cubic.

We then computed activities using both expressions (3) and, since the octahedral site is smaller than the cubic site assumed either that all of the excess cubic site atoms were $\mathrm{Mg}$ (smaller than $\mathrm{Fe}^{2+}$ ) or that they were $75 \% \mathrm{Mg}$ and $25 \% \mathrm{Fe}^{2+}$. Use of the first activity expression in (3) yields the highest oxygen fugacities and it is these, which are shown on Figure 3. Use of the second expression with all "excess" cubic atoms as $\mathrm{Mg}$ yields values on average $0.6 \log f \mathrm{O}_{2}$ units lower, while the allocation of $75 \%$ of the excess cubic atoms to $\mathrm{Mg}$ and $25 \%$ to $\mathrm{Fe}^{2+}$ means that average oxygen fugacities are $0.9 \log f_{\mathrm{O} 2}$ units lower than shown. However, the addition of activity coefficient terms, currently unknown, for octahedral site interactions involving $\mathrm{Mg}, \mathrm{Si}$ and $\mathrm{Fe}^{3+}$ would, we believe, tend to shift calculated oxygen fugacities to values higher than shown. Hence we consider that the simpler activity expression of (3) provides a reasonable compromise. In support of this conclusion we observe that 4 of the 5 iron metal-saturated experiments of Rohrbach et $\mathrm{al}^{24}$ plot correctly in the Fe stability field of Figure 3 and that only one of our 13 inclusions plots just into the Fe stability field. It should also be noted that, although the absolute uncertainties must be of the order of $1 \log$ unit in $f \mathrm{O}_{2}$, errors in the activity expressions would shift all points up and down by similar amounts, thus preserving the trends observed in Figure 3.

Data for the IW $(\mathrm{Fe}-\mathrm{FeO})$ buffer $^{41}$ at 1 atmosphere were fitted to 1/T to enable extrapolation to high temperature. They were extrapolated in pressure using the Murnaghan equation of state with volumes, thermal expansion coefficients and bulk moduli from a Handbook of Physical Constants ${ }^{42}$.

\section{Methods References}

31 Potapkin, V. et al. The 57Fe synchrotron Mössbauer source at the ESRF. Journal of synchrotron radiation 19, 559-569 (2012). 
32 Nestola, F. et al. Synchrotron Mössbauer Source technique for in situ measurement of iron-bearing inclusions in natural diamonds. Lithos 265, 328333, doi:http://dx.doi.org/10.1016/j.lithos.2016.06.016 (2016).

33 Prescher, C., McCammon, C. \& Dubrovinsky, L. MossA: a program for analyzing energy-domain Mössbauer spectra from conventional and synchrotron sources. Journal of Applied Crystallography 45, 329-331 (2012).

34 Geiger, C. A. et al. A combined temperature dependent ${ }^{57} \mathrm{Fe}$ Mössbauer and single crystal X-ray diffraction study of synthetic almandine: evidence for the Goldanskii-Karyagin effect. Physics and Chemistry of Minerals 19, 121-126 (1992).

35 Lyubutin, I. \& Dodokin, A. Temperature dependence of Mössbauer effect for $\mathrm{Fe} 2+$ in dodecahedral coordination in garnet. . SOVIET PHYSICS CRYSTALLOGRAPHY, USSR 15, 1091 (1971).

36 Lyubutin, I., Dodokin, A. \& Belyaev, L. Temperature dependence of Mössbauer effect for octahedral iron atoms in garnets. SOVIET PHYSICS SOLID STATE, USSR 12, 1100 (1970).

37 Liermann, H. P. et al. The extreme conditions beamline P02.2 and the extreme conditions science infrastructure at PETRA III. Journal of synchrotron radiation 22, 908-924, doi:10.1107/S1600577515005937 (2015).

38 Agilent Technologies. CrysAlisPro Software system (2013).

39 Petř́čcek, V., Dušek, M. \& Palatinus, L. Crystallographic computing system JANA2006: general features. Zeitschrift für Kristallographie-Crystalline Materials 229, 345-352 (2014).

40 Stagno, V., Ojwang, D. O., McCammon, C. A. \& Frost, D. J. The oxidation state of the mantle and the extraction of carbon from Earth's interior. Nature 493, 84-88, doi:Doi 10.1038/Nature11679 (2013).

41 Holmes, R. D., O’Neill, H. S. C. \& Arculus, R. J. Standard Gibbs free energy of formation for $\mathrm{Cu}_{2} \mathrm{O}, \mathrm{NiO}, \mathrm{CoO}$, and $\mathrm{Fe}_{\mathrm{x}} \mathrm{O}$ : high-resolution electrochemical measurements using zirconia solid electrolytes from 900-1400 K. Geochimica Et Cosmochimica Acta 50, 2439-2452, doi:Doi 10.1016/0016-7037(86)90027-X (1986).

42 Ahrens, T. J. in Mineral Physics and Crystallography, A Handbook of Physical Constants, AGU Reference Shelf (American Geophysical Union, 1995). 